\title{
Metastatic Breast Cancer: Is There a Differential Therapy Efficacy between Visceral and Non-Visceral Metastatic Breast Cancer?
}

\author{
Thomas Kolben Maximilian Bardenhewer Theresa M. Kolben Laura Rickerl \\ Tom Degenhardt Sven Mahner Nadia Harbeck Rachel Wuerstlein \\ Department of Obstetrics and Gynecology, Breast Center, University Hospital, LMU Munich, Munich, Germany
}

\section{Keywords}

Metastatic breast cancer · Therapy efficacy · Visceral metastasis · Non-visceral metastasis

\begin{abstract}
Purpose: Differential efficacy of newly registered therapies in subgroups of metastatic breast cancer (MBC) is an important consideration for subsequent use in clinical practice. Unfortunately, such subgroup analyses often are exploratory and rarely statistically adequately powered and may thus be misleading. This analysis aimed to explore a potentially different treatment response to i.v. therapies between visceral and non-visceral MBC. Methods: In a systematic literature analysis (PubMed) comprising phase III registration studies for MBC from 1994 to 2014, differences in outcome were evaluated regarding progression-free survival, time to progression, overall survival (OS), and visceral versus nonvisceral disease. The impact of HER2 and hormone receptor status was also considered. A total of 16 studies comprising 13,083 patients were selected by considering the information given in the medical product's professional information and the decision of the US Food and Drug Administration or the European Medicine Agency for approval of the respective therapeutic agents now used in the treatment of MBC. Results: No statistically significant differences regarding treatment response and therapy benefit were found in MBC patients with visceral versus non-visceral metastases based on reported hazard ratios and confidence intervals in registration trials. Interesting but nonsignificant differences were found regarding a distinct therapy benefit regarding differ-
\end{abstract}

ent metastasis locations in 4 studies. Conclusion: For targeted i.v. therapies based on biomarker selection, there is a trend - although not significant - toward a benefit (OS) from combination therapies favoring visceral disease. However, at the present time, metastasis localization should not be used as a predictive marker for choice of systemic therapy in MBC.

(c) 2019 S. Karger AG, Basel

\section{Introduction}

Primary metastatic breast cancer (MBC) amounts to about $5-10 \%$ of all breast cancer patients [1]; about 20 $30 \%$ of breast cancer patients will experience metastatic disease during the course of their disease. Median survival is $2-3$ years, and long-term survival $>5$ years is still rare with only about $25 \%$ [2].

In the treatment of $\mathrm{MBC}$, there is a great variety of different therapeutic agents from the field of endocrine therapy, targeted therapy, or chemotherapy. The decision for a specific therapy regimen mainly depends on the pattern of metastasis, the intrinsic subtype, and the clinical presentation and on whether a rapid remission is required. Tumor biology and prior treatments but also the patient's general condition and preferences are additional criteria for treatment choice.

Clinically, it is a very relevant question whether there is an efficacy difference of certain therapies according to site of metastasis. Unfortunately, given the diversity of the available study data for $\mathrm{MBC}$ and their inhomogeneous in- and exclusion criteria, the therapy effect in visceral 
Table 1. Overview of the results of the analyzed trials differentiated according to site of metastases (visceral vs. non-visceral)

\begin{tabular}{|c|c|c|c|c|c|c|c|c|c|}
\hline & Therapy regimen & $\begin{array}{l}\text { End- } \\
\text { point }\end{array}$ & $\begin{array}{l}\mathrm{HR} \\
\text { total }\end{array}$ & $\mathrm{CI}$ & $p$ value & $\begin{array}{l}\text { Visceral } \\
\text { metastases }\end{array}$ & CI & $\begin{array}{l}\text { Non-visceral } \\
\text { metastases }\end{array}$ & CI \\
\hline \multicolumn{10}{|c|}{ HER2 positive } \\
\hline [3] & $\mathrm{L}+\mathrm{Tr}$ vs. $\mathrm{L}$ & OS & 0.74 & $0.57-0.97$ & na & $<0.8$ & $<1.00$ & $<0.8$ & $>1.00$ \\
\hline [4] & $\mathrm{L}+\mathrm{Tr}$ vs. $\mathrm{L}$ & PFS & 0.73 & $0.57-0.93$ & 0.008 & $0.6-0.8$ & $<1.00$ & $0.8-1.00$ & $>1.4$ \\
\hline [5] & T-D vs. $\mathrm{L}+\mathrm{C}$ & PFS & 0.65 & $0.55-0.77$ & $<0.001$ & 0.55 & $0.45-0.67$ & 0.96 & $0.71-1.30$ \\
\hline \multirow[t]{2}{*}{ [6] } & $\mathrm{P}+\mathrm{Tr}+\mathrm{D}$ vs. $\mathrm{Tr}+\mathrm{D}$ & PFS & 0.69 & $0.58-0.81$ & na & 0.63 & $0.53-0.76$ & 0.89 & $0.61-1.31$ \\
\hline & & OS & 0.66 & $0.52-0.84$ & 0.0008 & 0.57 & $0.44-0.74$ & 1.42 & $0.71-2.84$ \\
\hline [7] & $\mathrm{L}+\mathrm{Le}$ vs. Le & PFS & 0.71 & $0.53-0.96$ & na & $0.6-0.8$ & $<1.00$ & $0.8-1.00$ & $>1.20$ \\
\hline \multicolumn{10}{|c|}{ HER2 unknown } \\
\hline [8] & Le vs. T & TTP & 0.70 & $0.6-0.82$ & na & 0.69 & $0.55-0.87$ & 0.73 & $0.53-1.00$ \\
\hline [9] & T vs. A & TTP & 1.13 & $\geq 1.00$ & na & $>1.00$ & crossing 1.00 & $>1.00$ & crossing 1.00 \\
\hline [10] & Dox vs. PLD & PFS & 1.00 & $0.82-1.22$ & na & $1.00-1.20$ & $<1.00$ & $0.8-1.00$ & crossing 1.00 \\
\hline [11] & A vs. megestrol acetate & TTP & 0.97 & $0.75-1.24$ & na & \multicolumn{4}{|c|}{ no differences, no numbers available } \\
\hline [12] & F 500 mg vs. F 250 mg & PFS & 0.8 & $0.68-0.94$ & 0.006 & $0.8-1.00$ & $\leq 1.00$ & $<0.8$ & $<1.00$ \\
\hline \multicolumn{10}{|c|}{ HER2 negative } \\
\hline \multirow[t]{2}{*}{ [13] } & $\mathrm{C}+\mathrm{BV}$ vs. $\mathrm{C}+\mathrm{PL}$ & PFS & 0.69 & $0.56-0.84$ & na & 0.72 & $0.57-0.9$ & 0.58 & $0.4-0.83$ \\
\hline & $\begin{array}{l}\mathrm{Ta}+\mathrm{An}+\mathrm{BV} \text { vs. } \\
\mathrm{Ta}+\mathrm{An}+\mathrm{PL}\end{array}$ & PFS & 0.64 & $0.52-0.8$ & na & 0.68 & $0.54-0.86$ & 0.63 & $0.42-0.94$ \\
\hline [14] & $\mathrm{Pa}+\mathrm{BV}$ vs. $\mathrm{Pa}$ & PFS & 0.6 & $0.51-0.7$ & na & 0.59 & $0.49-0.79$ & 0.63 & $0.4-0.97$ \\
\hline [15] & $\mathrm{Pa}+\mathrm{BV}$ vs. $\mathrm{Pa}$ & PFS & 0.48 & $0.385-0.607$ & $<0.0001$ & 0.58 & $0.46-0.72$ & 0.28 & $0.1-0.79$ \\
\hline$[16]$ & $\mathrm{CT}+\mathrm{BV}$ vs. $\mathrm{CT} \mathrm{PL}$ & PFS & 0.78 & $0.64-0.93$ & na & 0.77 & $0.62-0.96$ & 0.74 & $0.5-1.07$ \\
\hline \multirow[t]{2}{*}[17]{} & BV vs. non-BV & PFS & 0.64 & $0.57-0.71$ & na & 0.66 & $0.59-0.75$ & 0.6 & $0.49-0.74$ \\
\hline & & OS & 0.97 & $0.86-1.08$ & na & 0.96 & $0.85-1.09$ & 1.07 & $0.85-1.35$ \\
\hline [18] & $\mathrm{Ev}+\mathrm{Ex}$ vs. Ex & PFS & 0.45 & $0.38-0.54$ & na & 0.47 & $<0.7$ & 0.41 & $<0.7$ \\
\hline
\end{tabular}

A, anastrozole; BV, bevacizumab; C, capecitabine; CI, confidence interval; D, docetaxel; Dox, doxorubicin; Ev, everolimus; Ex, exemestane; F, fulvestrant; HR, hazard ratio; L, lapatinib; Le, letrozole; na, not available; OS, overall survival; P, pertuzumab; Pa, paclitaxel; PL, placebo; PFS, progession-free survival; PLD, pegylated liposomal doxorubicin; T, tamoxifen; Ta+An, taxane + anthracycline; T-D, T-DM1; Tr, trastuzumab; TTP, time to progression.

versus non-visceral disease has mostly been addressed by subgroup analyses within individual trials. Moreover, visceral and non-visceral disease was defined differently in individual studies with different organ systems being included into the individual definition (see below). This made classification and correlation with clinical outcome difficult. We sought to detect differences in therapy benefit in MBC patients with visceral versus non-visceral metastasis using outcome (e.g., progression-free survival [PFS], time to progression [TTP], and overall survival $[\mathrm{OS}])$ as a surrogate. Per definition, PFS includes all deaths, while deaths before progression are censored with TTP. If available, tumor biology as indicated by HER2 and hormone receptor (HR) status was also considered.

\section{Material and Search Methods}

A systematic literature search ( $n=6,362$ hits) in the meta-database PubMed of the US National Library of Medicine was performed, reviewing the publishing period from 1994 to 2014 for registration trials in $\mathrm{MBC}$ with appropriate search terms such as "metastatic breast cancer," "clinical trial," "phase III study," and "visceral metastasis."

We included 257 studies ( $n=126,291$ patients) into our analysis. Among those 257 studies, we identified 69 studies which had published separate data for visceral (defined as the presence of visceral metastases independent of the presence of other metastatic sites) versus non-visceral (defined as non-visceral metastases in the absence of visceral involvement) disease. These included phase III trials plus the respective subsequent secondary publications.

Visceral metastases were defined by the following locations: liver, lung, ascites, pleural effusion, and metastases in the central nervous system. Non-visceral metastases were defined as bone, skin, and lymph node metastases. Out of these 69 studies, we selected 16 studies ( $n=13,083$ patients) by considering (a) the information given in the SmPC (Summary of Product Characteristics) and (b) the decision of the US Food and Drug Administration (FDA) or the European Medicine Agency (EMA) for approval of the respective therapeutic agents for MBC. The selected 17 studies all reported the outcome endpoints mentioned above [3-19]. In order to achieve comparability, we extracted the information for metastasis pattern, hazard ratios, and confidence intervals as well as times in weeks (if available) for PFS, TTP, and OS of the entire study population divided into three main groups according to HER2 status: HER2-positive, HER2-negative, and unknown HER2 status. These main groups then were stratified by HR status of the study population into subgroups. HR-positive and HR-all (i.e., independent of HR status) subgroups were found. No studies reported on "visceral versus non-visceral in the subgroups": HRnegative and HR-unknown (i.e., HR status not reported). Regarding the group of HR-all, where available, the respective study results are additionally shown for HR-positive and -negative groups. The information whether therapy response was different or similar in visceral versus non-visceral was taken from the respective hazard ratios and confidence intervals. 

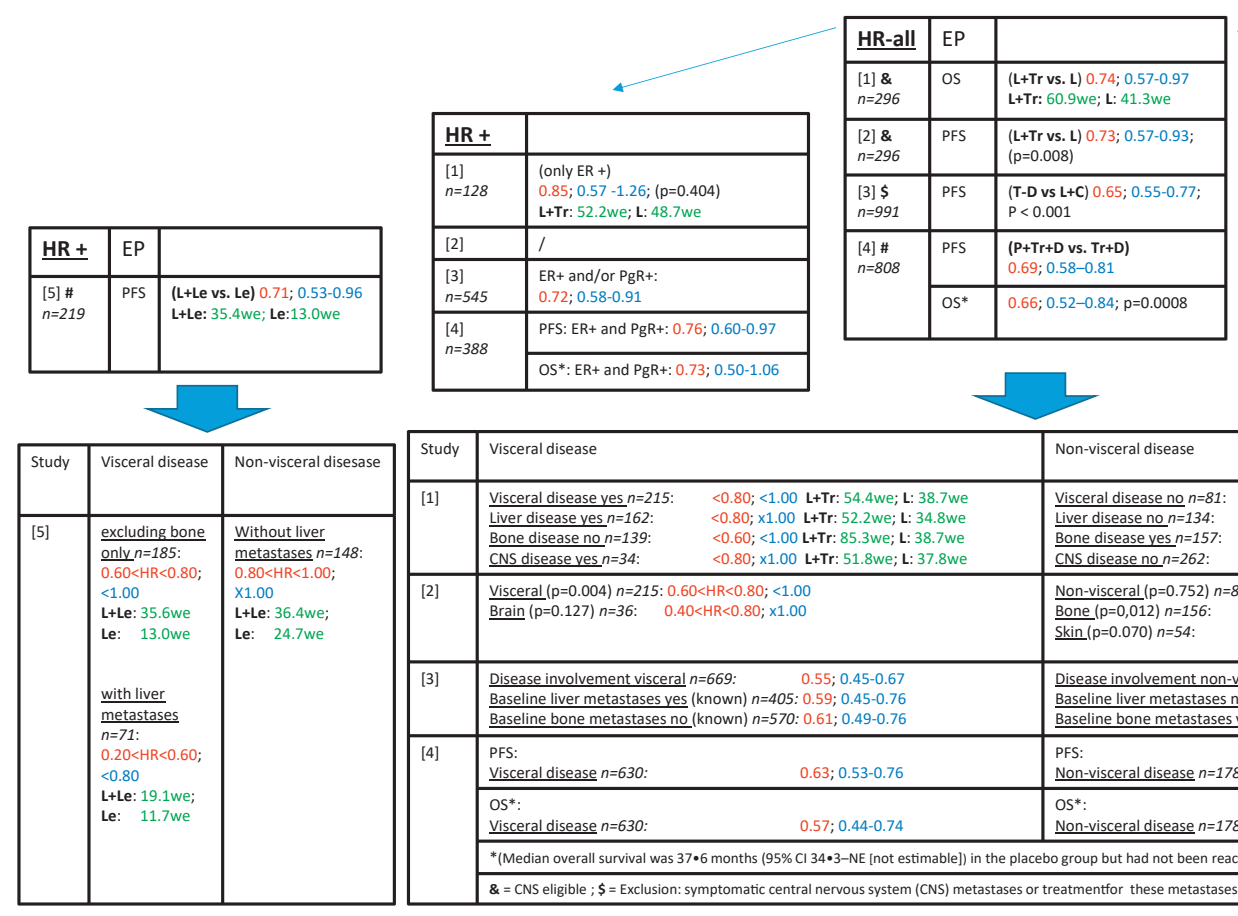

\begin{tabular}{|c|c|c|c|c|}
\hline Study & \multicolumn{2}{|l|}{ Visceral disease } & \multicolumn{2}{|l|}{ Non-visceral disease } \\
\hline [1] & $\begin{array}{l}\text { Visceral disease yes } n=215: \\
\text { Liver disease yes } n=162: \\
\text { Bone disease no } n=139: \\
\text { CNS disease yes } n=34:\end{array}$ & $\begin{array}{l}<0.80 ;<1.00 \text { LtTr: } 54.4 \mathrm{we} ; \mathrm{L}: 38.7 \mathrm{we} \\
<0.80 ; \times 1.00 \text { L+Tr: } 52.2 \mathrm{we} ; \mathrm{L}: 34.8 \mathrm{we} \\
<0.60 ;<1.00 \text { L+Tr: } 85.3 \mathrm{we} ; \mathrm{L}: 38.7 \mathrm{we} \\
<0.80 ; \times 1.00 \text { L+Tr: } 51.8 \mathrm{w} ; \mathrm{L}: 37.8 \mathrm{we}\end{array}$ & $\begin{array}{l}\text { Visceral disease no } n=81 \text { : } \\
\text { Liver disease no } n=134: \\
\text { Bone disease ves } n=157: \\
\text { CNS disease no } n=262:\end{array}$ & $\begin{array}{l}<0.80 ; \times 1.00 \text { L+Tr: } 86.1 \text { we; L: } 49.2 \mathrm{we} \\
<0.80 ; \times 1.00 \text { L+Tr: } 77.0 \mathrm{we} ; \mathrm{L}: 49.2 \mathrm{we} \\
>1.00 ; \times 1.00 \mathrm{~L}+\mathrm{Tr}: 45.7 \mathrm{we} ; \mathrm{L}: 45.7 \mathrm{we} \\
<0.80 ;<1.00 \mathrm{~L}+\mathrm{Tr}: 63.51 \mathrm{we} ; \mathrm{L}: 45.7 \mathrm{we}\end{array}$ \\
\hline [2] & \multicolumn{2}{|c|}{$\begin{array}{l}\text { Visceral }(p=0.004) n=215: 0.60<H R<0.80 ;<1.00 \\
\text { Brain }(p=0.127) n=36: \quad 0.40<H R<0.80 ; x 1.00\end{array}$} & \multicolumn{2}{|c|}{$\begin{array}{lc}\text { Non-visceral }(p=0.752) n=81: 0.80<H R<1.00 ; \times 1.00 \\
\text { Bone }(p=0,012) n=156: & 0.60<H R<0.80 ;<1.00 \\
\text { Skin }(p=0.070) n=54: & 0.40<H R<0.80 ; \times 1.00\end{array}$} \\
\hline [3] & \multicolumn{2}{|c|}{$\begin{array}{lr}\text { Disease involvement visceral } n=669: & 0.55 ; 0.45-0.67 \\
\text { Baseline liver metastases yes (known) } n=405: 0.59 ; 0.45-0.76 \\
\text { Baseline bone metastases no (known) } n=570: 0.61 ; 0.49-0.76\end{array}$} & \multicolumn{2}{|c|}{$\begin{array}{lc}\text { Disease involvement non-visceral } n=322: & 0.96 ; 0.71-1.30 \\
\text { Baseline liver metastases no (known) } n=577: & 0.71 ; 0.57-0.89 \\
\text { Baseline bone metastases ves (known) } n=399: 0.76 ; 0.58-0.99\end{array}$} \\
\hline \multirow[t]{2}{*}{ [4] } & \multicolumn{2}{|l|}{$\begin{array}{l}\text { PFS: } \\
\text { Visceral disease } n=630:\end{array}$} & \multicolumn{2}{|c|}{$\begin{array}{l}\text { PFS: } \\
\text { Non-visceral disease } n=178:\end{array}$} \\
\hline & \multicolumn{2}{|l|}{$\begin{array}{l}\text { OS*: } \\
\text { Visceral disease } n=630 \text { : }\end{array}$} & \multicolumn{2}{|c|}{$\begin{array}{ll}\text { OS*: } & \\
\text { Non-visceral disease } n=178: & 1.42 ; 0.71-2.84\end{array}$} \\
\hline
\end{tabular}

Fig. 1. Overview and analysis of trials including a HER2-positive study population; stratification by hormone receptor status (HR+ vs. HR-) and metastasis localization (visceral vs. non-visceral). ER, estrogen receptor; $\mathrm{HR}+/$-/all, hormone receptor status positive/ negative/all (i.e., independent of HR status); L, lapatinib; Le, letrozole; OS, overall survival; $\mathrm{PR} / \mathrm{PgR}$, progesterone receptor; PFS, progression-free survival; T-D, T-DM1 (trastuzumab-emtansine); $\mathrm{Tr}$, trastuzumab. The therapeutical regimes with an increased benefit (smaller hazard ratio) are shown on the left side (for example: $\mathrm{Y}+\mathrm{Z}$ vs. Z). Red numerals = hazard ratio. Blue numerals $=$ confidence intervals $(95 \%) ; \times 1=$ crossing 1 . Green numerals $=$ time in weeks (we).

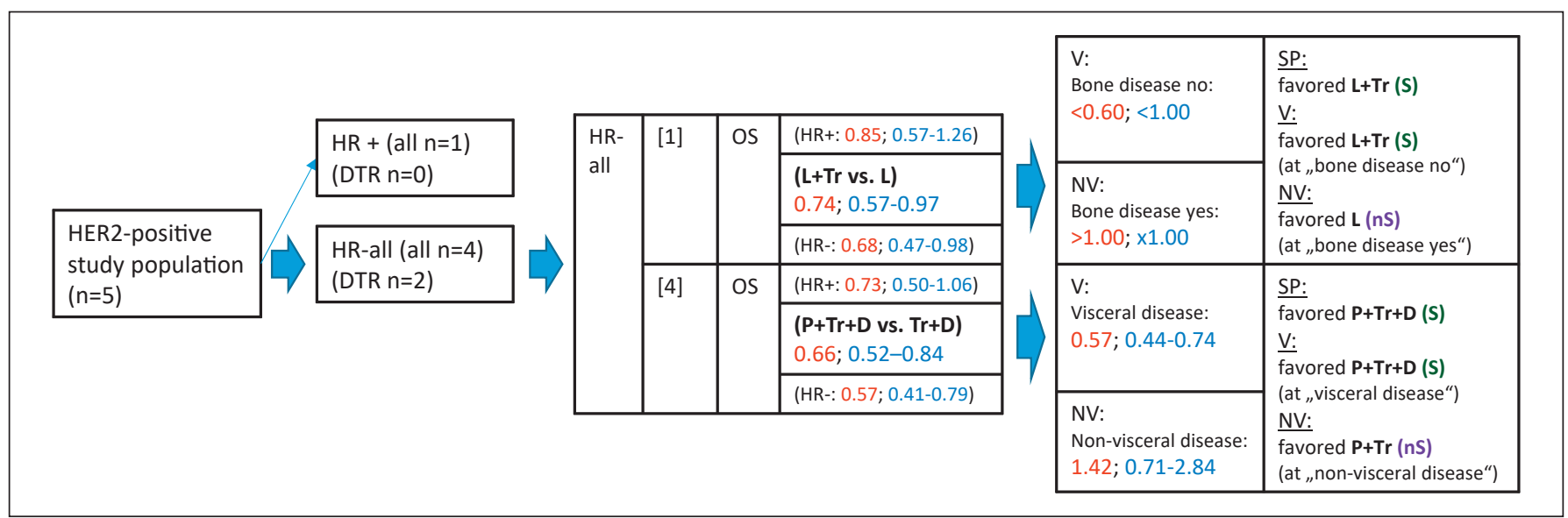

Fig. 2. Differences in therapy response in the HER2-positive study population. DTR, different therapy response; HR +/-/all, hormone receptor status positive/negative/all (i.e., independent of $\mathrm{HR}$ status); L, lapatinib; NV, non-visceral disease; OS, overall survival; $\mathrm{P}$, pertuzumab; $\mathrm{Tr}$, trastuzumab; $\mathrm{V}$, visceral disease; $\mathrm{nS}$, statisti-

Regimes with a differential therapy benefit were defined by a hazard ratio distinct from 1.00 and a confidence interval not overlapping 1.00. Trends toward better, worse, or similar response to therapy (i.e., hazard ratio distinct from 1.00 but confidence interval overlapping with 1.00) were also reported. cally not significant; S, statistically significant. The therapeutical regimes with an increased benefit (smaller hazard ratio) are shown on the left side (for example: $\mathrm{Y}+\mathrm{Z}$ vs. $\mathrm{Z}$ ). Red numerals = hazard ratio. Blue numerals $=$ confidence intervals $(95 \%) ; \times 1=$ crossing 1. Green numerals = time in weeks (we).

Trials were first looked at on an individual trial basis, then results were also summarized. We were not able to perform a formal meta-analysis as there were only 16 trials in the final set which differed rather substantially regarding lines of therapy, drugs used, etc. 

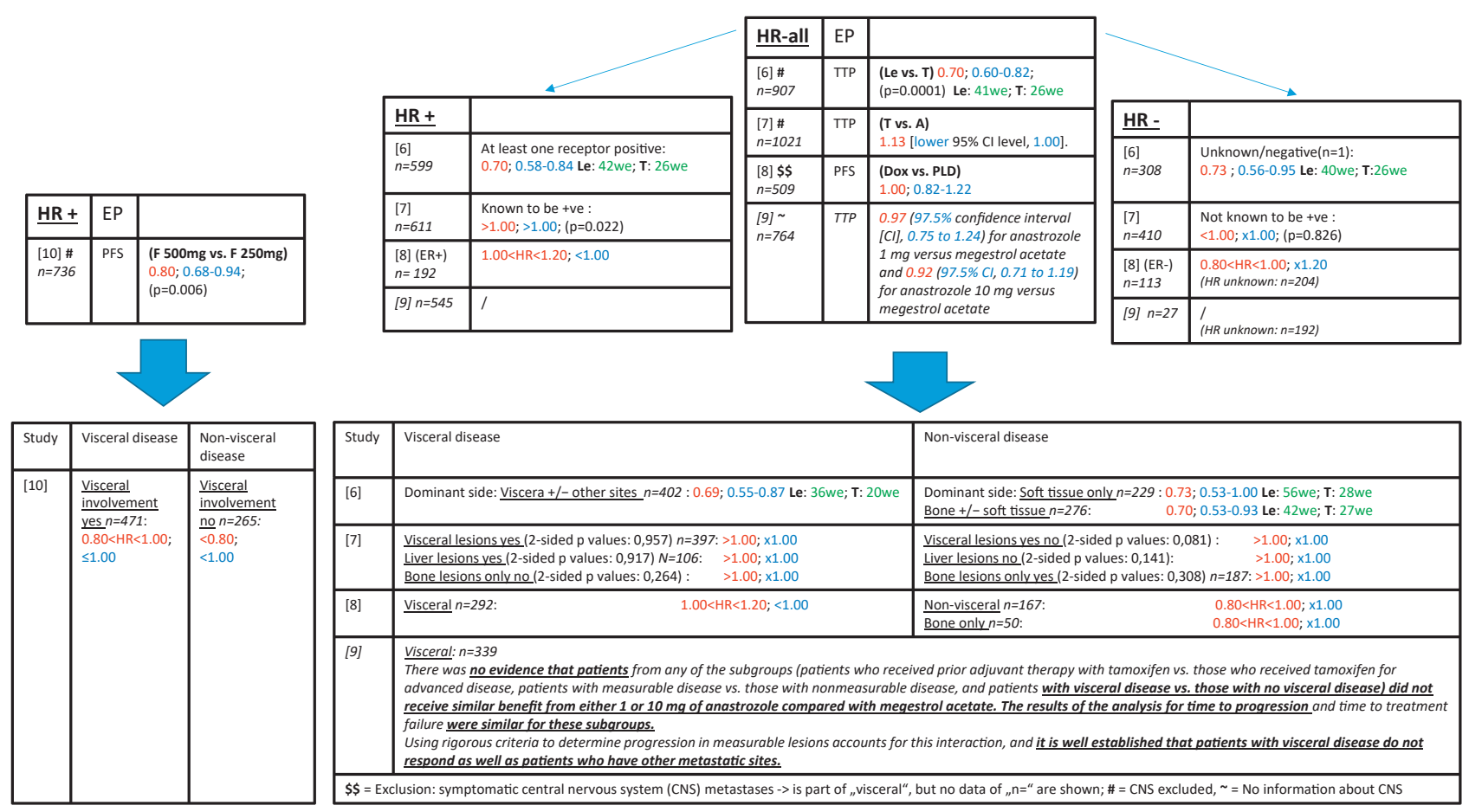

\begin{tabular}{|c|c|c|}
\hline Study & Visceral disease & Non-visceral disease \\
\hline [6] & Dominant side: Viscera +/- other sites $n=402: 0.69 ; 0.55-0.87$ Le: 36 we; T: 20 we & $\begin{array}{l}\text { Dominant side: Soft tissue only } n=229: 0.73 ; 0.53-1.00 \text { Le: } 56 \text { we; T: } 28 \text { we } \\
\begin{array}{ll}\text { Bone }+ \text { - soft tissue } n=276: & 0.70 ; 0.53-0.93 \text { Le: } 42 \text { we; } \text { : } 27 \text { we }\end{array}\end{array}$ \\
\hline [7] & $\begin{array}{ll}\text { Visceral lesions yes }(2-\text { sided } p \text { values: } 0,957) n=397:>1.00 ; \times 1.00 \\
\text { Liver lesions yes (2-sided } p \text { values: } 0,917) N=106: & >1.00 ; \times 1.00 \\
\text { Bone lesions only no }(2 \text {-sided } p \text { values: } 0,264): & >1.00 ; \times 1.00\end{array}$ & $\begin{array}{lr}\text { Visceral lesions yes no (2-sided } p \text { values: } 0,081): & >1.00 ; \times 1.00 \\
\text { Liver lesions no (2-sided } p \text { values: } 0,141): & >1.00 ; \times 1.00 \\
\text { Bone lesions only yes (2-sided p values: } 0,308) n=187: & >1.00 ; \times 1.00\end{array}$ \\
\hline [8] & $1.00<H R<1.20 ;<1.00$ & $\begin{array}{l}0.80<H R<1.00 ; \times 1.00 \\
0.80<H R<1.00 ; \times 1.00\end{array}$ \\
\hline [9] & $\begin{array}{l}\text { Visceral: } n=339 \\
\text { There was no evidence that patients from any of the subgroups (patients who rece } \\
\text { advanced disease, patients with measurable disease vs. those with nonmeasurable } \\
\text { receive similar benefit from either } 1 \text { or } 10 \mathrm{mg} \text { of anastrozole compared with meg } \\
\text { failure were similar for these subgroups. } \\
\text { Using rigorous criteria to determine progression in measurable lesions accounts for } \\
\text { respond as well as patients who have other metastatic sites. }\end{array}$ & $\begin{array}{l}\text { ed prior adjuvant therapy with tamoxifen vs. those who received tamoxifen for } \\
\text { isease, and patients with visceral disease vs. those with no visceral disease) did not } \\
\text { trol acetate. The results of the analysis for time to progression and time to treatment } \\
\text { his interaction, and it is well established that patients with visceral disease do not }\end{array}$ \\
\hline
\end{tabular}

Fig. 3. Overview and analysis of trials including a study population with unknown HER2 status; stratification by hormone receptor status (HR+ vs. HR-) and metastasis localization (visceral vs. non-visceral). A, anastrozole; F, fulvestrant; HR +/-/all, hormone receptor status positive/negative/all (i.e., independent of HR status); Le, letrozole; PFS, progression-free survival; T, tamoxifen; Ta+An, taxane + anthracycline; TTP, time to progression. The therapeutical regimes with an increased benefit (smaller hazard ratio) are shown on the left side (for example: $\mathrm{Y}+\mathrm{Z}$ vs. Z). Red numerals = hazard ratio. Blue numerals $=$ con fidence intervals $(95 \%) ; \times 1=$ crossing 1 . Green numerals $=$ time in weeks (we).

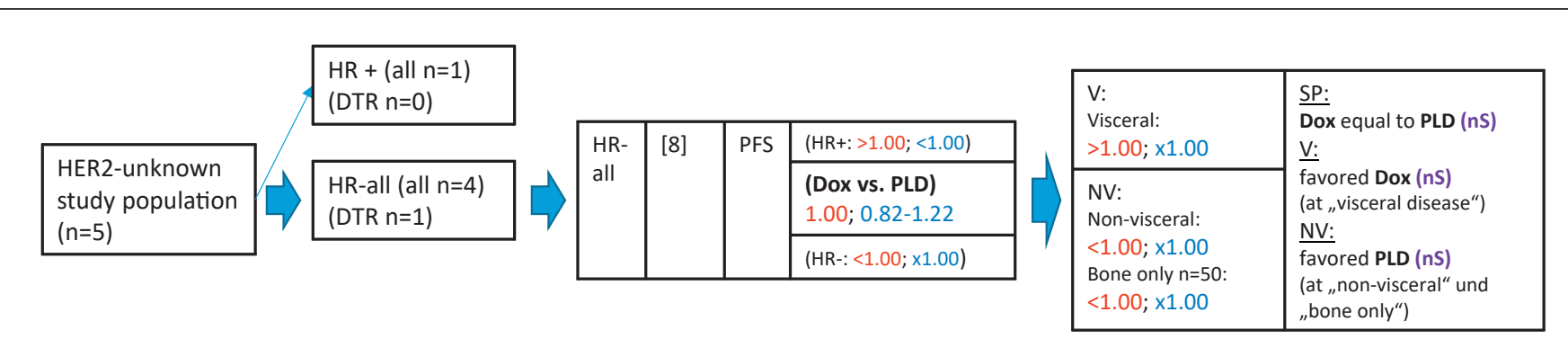

Fig. 4. Differences in therapy response in the HER2-unknown study population. Dox, doxorubicin; DTR, different therapy response; $\mathrm{HR}+/$ //all, hormone receptor status positive/negative/all (i.e., independent of HR status); NV, non-visceral disease; PFS, progression-free survival; PLD, pegylated liposomal doxorubicin;
$\mathrm{V}$, visceral disease; $\mathrm{nS}$, statistically not significant. The therapeutical regimes with an increased benefit (smaller hazard ratio) are shown on the left side (for example: $\mathrm{Y}+\mathrm{Z}$ vs. $\mathrm{Z}$ ). Red numerals = hazard ratio. Blue numerals = confidence intervals $(95 \%) ; \times 1=$ crossing 1. Green numerals = time in weeks (we).

\section{Results}

No statistically significant difference in treatment response and therapy benefit was found in MBC patients with visceral versus non-visceral metastases based on reported hazard ratios and confidence intervals in breast cancer registration trials. Interesting but not statistically

significant differences were found regarding a distinct therapy benefit of different metastases locations in four studies. Confidence intervals and $p$ values were taken directly from the publications. Table 1 gives an overview of the results of the analyzed trials including the differentiated presentation of the treatment effects in visceral compared to non-visceral metastasized patients. 


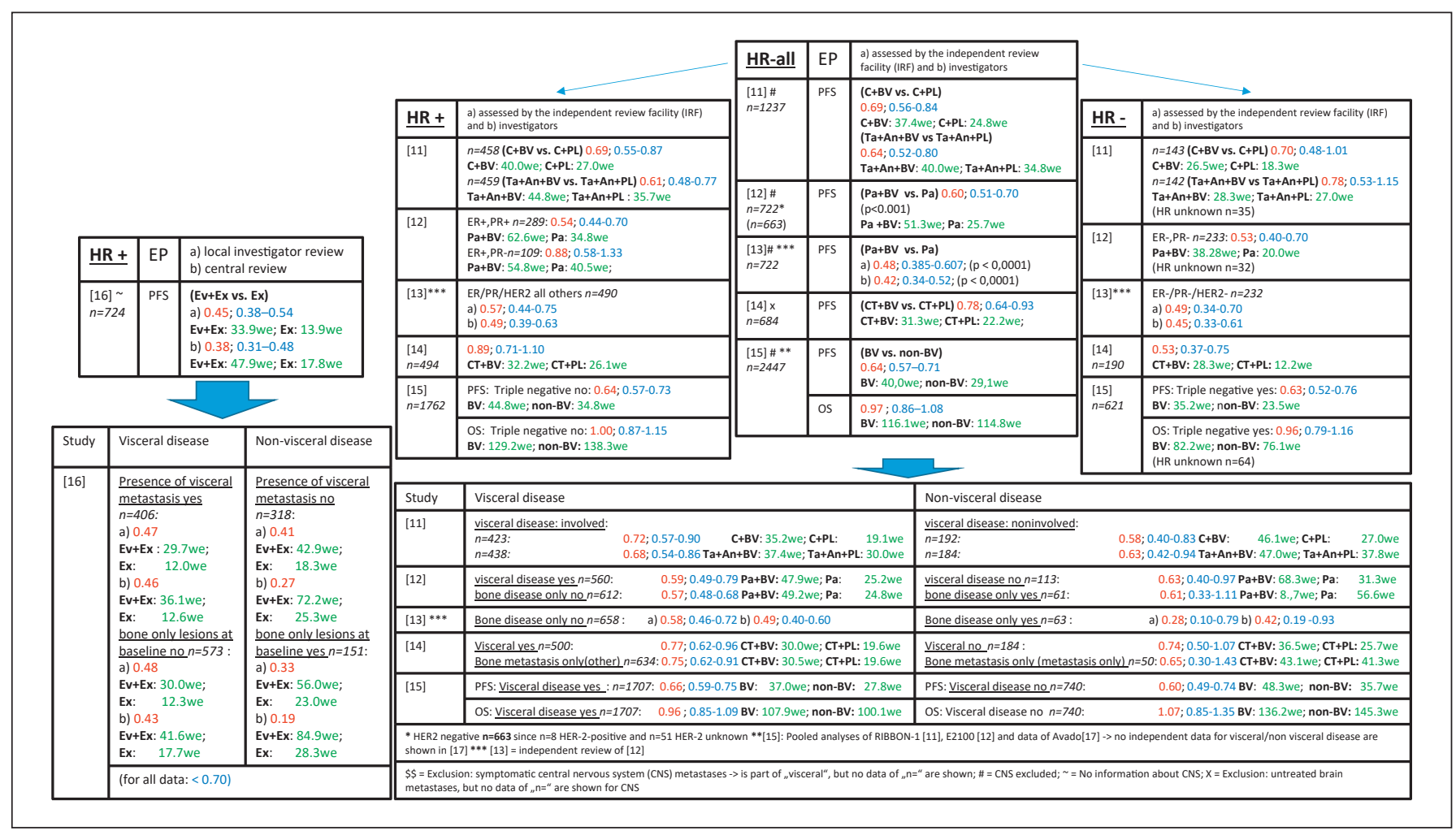

Fig. 5. Overview and analysis of trials including a HER2-negative study population; stratification by hormone receptor status (HR+ vs. HR-) and metastasis localization (visceral vs. non-visceral). $\mathrm{BV}$, bevacizumab; BV vs. non-BV, therapy with bevacizumab/ without bevacizumab; C, capecitabine; CT, chemotherapy; Ev, everolimus; Ex, exemestane; HR +/-/all, hormone receptor status positive/negative/all (i.e., independent of HR status); OS, overall survival; $\mathrm{Pa}$, paclitaxel; $\mathrm{PL}$, placebo; $\mathrm{PR} / \mathrm{PgR}$, progesterone receptor; PFS, progression-free survival; Ta+An, taxane + anthracycline. The therapeutical regimes with an increased benefit (smaller hazard ratio) are shown on the left side (for example: $\mathrm{Y}+\mathrm{Z}$ vs. $Z$ ). Red numerals = hazard ratio. Blue numerals $=$ confidence intervals $(95 \%) ; \times 1=$ crossing 1 . Green numerals $=$ time in weeks (we).

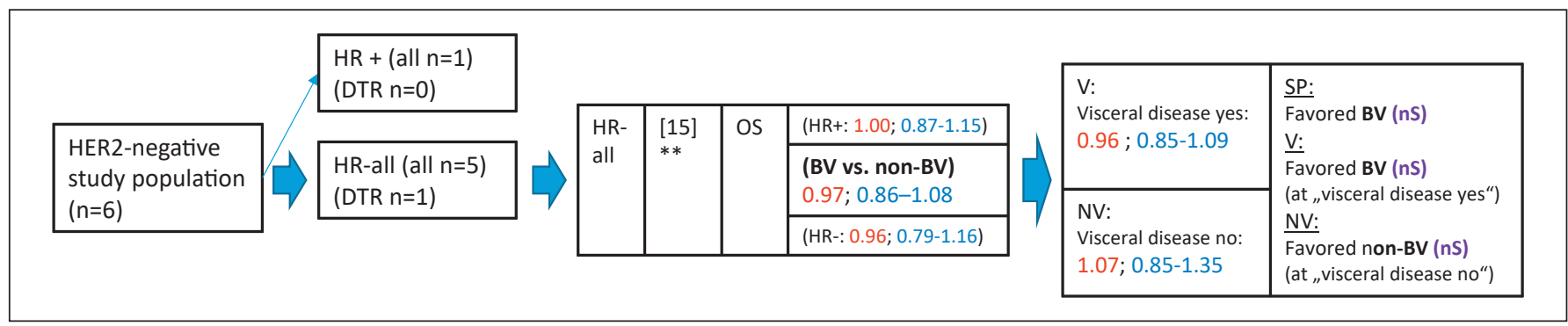

Fig. 6. Differences in therapy response in the HER2-negative study population. BV, bevacizumab; BV vs. non-BV, therapy with bevacizumab/without bevacizumab; DTR, different therapy response; $\mathrm{HR}+$ /-/all, hormone receptor status positive/negative/all (i.e., independent of HR status); NV, non-visceral disease; $\mathrm{V}$, visceral dis-

\section{HER2-Positive Tumors}

The collected data for the HER2-positive group are shown in Figure 1 and the differences found in this group are shown in an overview in Figure 2. Interesting but statistically nonsignificant differences were found in the HER2-positive group. There was an enhanced ease; nS, statistically not significant. The therapeutical regimes with an increased benefit (smaller hazard ratio) are shown on the left side (for example: $\mathrm{Y}+\mathrm{Z}$ vs. $\mathrm{Z}$ ). Red numerals = hazard ratio. Blue numerals = confidence intervals $(95 \%) ; \times 1=$ crossing 1 . Green numerals $=$ time in weeks (we). ses receiving modern combination therapies, i.e., lapatinib in combination with trastuzumab [3] or trastuzumab and docetaxel in combination with pertuzumab [6]. 


\section{HER2-Unknown Tumors}

The collected data for the HER2-unknown group are shown in Figure 3 and the differences found in this group are shown in an overview in Figure 4. For the group with unknown HER2 status, there was a numerical but not statistically significant difference in therapy response (PFS): patients with non-visceral disease seem to derive more therapy benefit from pegylated liposomal doxorubicin and patients with visceral disease from doxorubicin therapy [10]. Yet, it can be assumed that there is no clinically relevant difference as the respective hazard ratio and confidence interval of the total study population was 1.00 $(0.82-1.22)$, with an only minor deviation in visceral versus non-visceral disease.

\section{HER2-Negative Tumors}

The collected data of the HER2-negative group are shown in Figure 5 and the differences found in this group are shown in an overview in Figure 6. Within the HER2negative group, there was again a numerical but not statistically significant difference detected regarding therapy response (OS). Patients with non-visceral disease seem to derive more benefit from chemotherapy plus bevacizumab compared to patients with visceral disease and to the total population [17]. However, it can be assumed that there are no clinically relevant differences given a hazard ratio of 0.97 for the total study population (confidence interval: $0.86-1.08$ ), with only minor deviations for visceral versus non-visceral disease.

\section{Discussion}

There is a perception among many clinicians that visceral metastases respond less to certain therapies such as endocrine therapy and better to chemotherapy than nonvisceral metastases. Moreover, explorative, often retrospective analyses of small subgroups from large randomized trials also suggest differential therapy benefit according to metastasis localization. As such clinical perceptions may interfere with guideline-oriented therapy decisions, we undertook this systematic analysis of the literature in order to substantiate or dismiss these preconceived notions.

MBC has a median survival of about 24 months, with local relapses and lymph node metastases being associated with more favorable survival times than visceral disease [20]. OS after progression does not just differ according to relapse site (local relapse, lymph node relapse, distant metastasis) but also according to HR and HER2 status. In particular, OS after progression is very poor in triple negative disease [20]. Different breast cancer subtypes are correlated with different metastasis patterns [21].

In summary, we did not find a significant difference of therapy efficacy according to metastasis location in our analysis of breast cancer registration trials until 2014. It has to be noted that given the inhomogeneous nature of the published trials, we were only able to stratify according to HR and HER2 status.

In the future, it may well be that by subdividing MBC not just by HR and HER2 status but rather by molecular subtypes, there may be distinct therapeutic efficacy of certain agents according to metastatic site. Using rather simple stratification criteria such as HER2 or HR status, we were not able to detect such a difference in recent registration trials. Our observed lack of site-specific efficacy is in accordance with a review of 4 phase III randomized trials of first-line endocrine therapy. Overall, visceral metastases appeared to be as sensitive to endocrine therapy as non-visceral metastases [22].

Epidemiological data have not demonstrated differential survival according to treatment period and tumor biology [20]. It was thus reasonable to combine the registrations trials over 20 years from 1994 to 2014. Nevertheless, there are certainly limitations to our analyses: the vast majority of trials was not powered to show therapeutic efficacy by clinical subgroups such as by metastatic site. Moreover, terminology differed substantially between trials. Thus, our project demonstrates the difficulty to look at clinically relevant questions across several phase III trials. Besides in- and exclusion criteria or the definition of HR positivity versus negativity, also definitions of visceral and non-visceral metastases differ substantially between trials. For example, in some trials, central nervous system metastases are included with visceral metastases, in other trials they are considered a separate metastatic entity. Thus, it would be desirable to have unified definitions for future cross-trial comparisons as it was suggested for several items such as "endocrine resistance" or "visceral crisis" by the $\mathrm{ABC} 2$ consensus [23]. Furthermore, the impact of modern targeted therapies (i.e., CDK4/6 inhibitors, PD1 and PDL1 inhibitors) was not considered since our analysis only included studies published before 2014 .

\section{Conclusions}

We evaluated and stratified the registration trials in MBC until 2014 according to HER2 status and HR status and pattern of metastasis. In the published subgroup analyses, we did not find any significant differences in response rates for visceral versus non-visceral metastases. For targeted i.v. therapies based on biomarker selection, there is a numerical trend - although statistically not significant - toward a beneficial effect of combination therapies favoring visceral disease regarding OS. Therefore, at the present time, there is no evidence for a predictive value of metastasis localization regarding response to systemic therapy in the published registration trials in MBC. 
Patients should therefore receive guideline-recommended evidence-based therapies based on tumor biology (ER, PgR, HER2, PD-L1, gBRCA), response and toxicities to prior therapies, recurrence-free interval, general health, and life expectancy, as well as patients' preferences [24] but irrespective of their metastasis localization unless disease dynamics demand specific interventions.

\section{Statement of Ethics}

This article does not contain any studies with human participants performed by any of the authors.

\section{Disclosure Statement}

T. Kolben: spouse employed by Roche (employment started after this project was ended). T.M. Kolben: employee of Roche (employment started after this project was ended). S. Mahner: research support, advisory board, honoraria, travel support from: AstraZeneca, Bayer, Boehringer Ingelheim, Jenapharm, GSK, JanssenCilag, Medac, MSD, Pharmamar, Roche, Tesaro, Teva. N. Harbeck: honoraria for lectures and/or consulting from: Celgene, Novartis, Pfizer and Roche. All other authors have no conflicts of interest to declare.

\section{Funding Sources}

This study was supported by a research grant from Roche AG (grant number: RGRVR5037742).

\section{References}

1 Siegel R, Naishadham D, Jemal A. Cancer statistics, 2013. CA Cancer J Clin. 2013 Jan; 63(1):11-30.

2 Cardoso F, Costa A, Senkus E, Aapro M, André $\mathrm{F}$, Barrios $\mathrm{CH}$, et al. 3rd ESO-ESMO international consensus guidelines for Advanced Breast Cancer (ABC 3). Breast. 2017 Feb;31:244-59.

3 Blackwell KL, Burstein HJ, Storniolo AM, Rugo HS, Sledge G, Aktan G, et al. Overall survival benefit with lapatinib in combination with trastuzumab for patients with human epidermal growth factor receptor 2-positive metastatic breast cancer: final results from the EGF104900 Study. J Clin Oncol. 2012 Jul; 30(21):2585-92.

4 Blackwell KL, Burstein HJ, Storniolo AM, Rugo $\mathrm{H}$, Sledge $\mathrm{G}$, Koehler M, et al. Randomized study of Lapatinib alone or in combination with trastuzumab in women with ErbB2-positive, trastuzumab-refractory metastatic breast cancer. J Clin Oncol. 2010 Mar;28(7):1124-30.

5 Verma S, Miles D, Gianni L, Krop IE, Welslau M, Baselga J, et al.; EMILIA Study Group. Trastuzumab emtansine for HER2-positive advanced breast cancer. N Engl J Med. 2012 Nov;367(19):1783-91.

6 Swain SM, Kim SB, Cortés J, Ro J, Semiglazov $\mathrm{V}$, Campone $\mathrm{M}$, et al. Pertuzumab, trastuzumab, and docetaxel for HER2-positive metastatic breast cancer (CLEOPATRA study): overall survival results from a randomised, double-blind, placebo-controlled, phase 3 study. Lancet Oncol. 2013 May;14(6):461-71.

7 Schwartzberg LS, Franco SX, Florance A, O'Rourke L, Maltzman J, Johnston S. Lapatinib plus letrozole as first-line therapy for HER-2+ hormone receptor-positive metastatic breast cancer. Oncologist. 2010;15(2):122-9.

8 Mouridsen H, Gershanovich M, Sun Y, PérezCarrión R, Boni C, Monnier A, et al. Superior efficacy of letrozole versus tamoxifen as firstline therapy for postmenopausal women with advanced breast cancer: results of a phase III study of the International Letrozole Breast Cancer Group. J Clin Oncol. 2001 May; 19(10):2596-606

9 Bonneterre J, Buzdar A, Nabholtz JM, Robertson JF, Thürlimann B, von Euler M, et al.; In- vestigators Committee Members. Anastrozole is superior to tamoxifen as first-line therapy in hormone receptor positive advanced breast carcinoma. Cancer. 2001 Nov;92(9):2247-58.

10 O'Brien ME, Wigler N, Inbar M, Rosso R, Grischke E, Santoro A, et al.; CAELYX Breast Cancer Study Group. Reduced cardiotoxicity and comparable efficacy in a phase III trial of pegylated liposomal doxorubicin $\mathrm{HCl}$ (CAELYX/Doxil) versus conventional doxorubicin for first-line treatment of metastatic breast cancer. Ann Oncol. 2004 Mar;15(3):440-9.

11 Buzdar A, Jonat W, Howell A, Jones SE, Blomqvist C, Vogel CL, et al.; Arimidex Study Group. Anastrozole, a potent and selective aromatase inhibitor, versus megestrol acetate in postmenopausal women with advanced breast cancer: results of overview analysis of two phase III trials. J Clin Oncol. 1996 Jul; 14(7):2000-11.

12 Di Leo A, Jerusalem G, Petruzelka L, Torres $\mathrm{R}$, Bondarenko IN, Khasanov R, et al. Results of the CONFIRM phase III trial comparing fulvestrant $250 \mathrm{mg}$ with fulvestrant $500 \mathrm{mg}$ in postmenopausal women with estrogen receptor-positive advanced breast cancer. J Clin Oncol. 2010 Oct;28(30):4594-600.

13 Robert NJ, Diéras V, Glaspy J, Brufsky AM, Bondarenko I, Lipatov ON, et al. RIBBON-1: randomized, double-blind, placebo-controlled, phase III trial of chemotherapy with or without bevacizumab for first-line treatment of human epidermal growth factor receptor 2-negative, locally recurrent or metastatic breast cancer. J Clin Oncol. 2011 Apr;29(10):1252-60.

14 Miller K, Wang M, Gralow J, Dickler M, Cobleigh M, Perez EA, et al. Paclitaxel plus bevacizumab versus paclitaxel alone for metastatic breast cancer. N Engl J Med. 2007 Dec; 357(26):2666-76.

15 Gray R, Bhattacharya S, Bowden C, Miller K, Comis RL. Independent review of E2100: a phase III trial of bevacizumab plus paclitaxel versus paclitaxel in women with metastatic breast cancer. J Clin Oncol. 2009 Oct;27(30): 4966-72.

16 Brufsky AM, Hurvitz S, Perez E, Swamy R, Valero V, O'Neill V, et al. RIBBON-2: a randomized, double-blind, placebo-controlled, phase III trial evaluating the efficacy and safety of bevacizum$\mathrm{ab}$ in combination with chemotherapy for second-line treatment of human epidermal growth factor receptor 2-negative metastatic breast cancer. J Clin Oncol. 2011 Nov;29(32):4286-93.

17 Miles DW, Diéras V, Cortés J, Duenne AA, Yi J, O'Shaughnessy J. First-line bevacizumab in combination with chemotherapy for HER2negative metastatic breast cancer: pooled and subgroup analyses of data from 2447 patients. Ann Oncol. 2013 Nov;24(11):2773-80.

18 Yardley DA, Noguchi S, Pritchard KI, Burris HA 3rd, Baselga J, Gnant M, et al. Everolimus plus exemestane in postmenopausal patients with $\mathrm{HR}(+)$ breast cancer: BOLERO-2 final progression-free survival analysis. Adv Ther. 2013 Oct;30(10):870-84.

19 Miles DW, Chan A, Dirix LY, Cortés J, Pivot $\mathrm{X}$, Tomczak P, et al. Phase III study of bevacizumab plus docetaxel compared with placebo plus docetaxel for the first-line treatment of human epidermal growth factor receptor 2-negative metastatic breast cancer. J Clin Oncol. 2010 Jul;28(20):3239-47.

20 MunichCancerRegistry. Survival of patients with breast cancer metastases. Munich Cancer Registry of the Munich Comprehensive Cancer Center; 2018.

21 Savci-Heijink CD, Halfwerk H, Hooijer GK, Horlings HM, Wesseling J, van de Vijver MJ. Retrospective analysis of metastatic behaviour of breast cancer subtypes. Breast Cancer Res Treat. 2015 Apr;150(3):547-57.

22 Robertson JFR, Paridaens R, Bogaerts J, Rukazenkov Y, Campbell C, Bradbury I. Visceral metastases from hormone receptor positive breast cancer are as sensitive to endocrine therapy as non-visceral metastases [abstract]. In: Proceedings of the Thirty-Seventh Annual CTRCAACR San Antonio Breast Cancer Symposium: 2014 Dec 9-13; San Antonio, TX. Cancer Res 2015;75(9 Suppl):Abstract nr P1-13-02.

23 Cardoso F, Costa A, Norton L, Senkus E, Aapro M, André F, et al.; European School of Oncology; European Society of Medical Oncology. ESO-ESMO 2nd international consensus guidelines for advanced breast cancer (ABC2). Breast. 2014 Oct;23(5):489-502.

24 AGO Guidelines Breast Version 2019.1, 2019. 